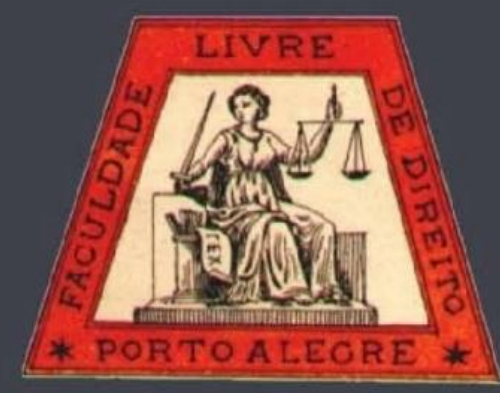

\title{
Ditadura e Democracia: o impacto da conciliação sobre as memórias e a constituição da Justiça de Transição no Brasil
}

Dictatorship and Democracy: the impact of conciliation on the memories and constitution of Transitional Justice in Brazil

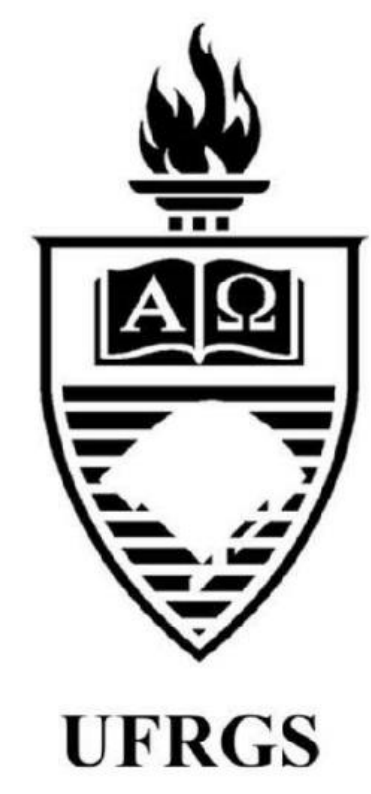

\author{
Alexandre Garcia Araújo \\ Universidade do Estado da Bahia
}

José Alves Dias

Universidade Estadual do Sudoeste da Bahia 


\title{
Ditadura e Democracia: o impacto da conciliação sobre as memórias e a constituição da Justiça de Transição no Brasil
}

\author{
Dictatorship and Democracy: the impact of conciliation on the memories and constitution of \\ Transitional Justice in Brazil
}

Alexandre Garcia Araújo*

José Alves Dias**

\begin{abstract}
REFERÊNCIA
ARAÚJO, Alexandre Garcia; DIAS, José Alves. Ditadura e Democracia: o impacto da conciliação sobre as memórias e a constituição da Justiça de Transição no Brasil. Revista da Faculdade de Direito da UFRGS, Porto Alegre, n. 38, p. 121-139, ago. 2018.
\end{abstract}

\section{RESUMO}

O propósito do artigo é demonstrar como o mecanismo da conciliação foi utilizado para superar a ditadura e retornar à democracia, impactando as memórias construídas sobre o período autoritário, e limitando a conformação de uma Justiça de Transição no Brasil. Os debates em torno do tema se acentuaram, sobremaneira, com a formação da Comissão Especial de Mortos e Desaparecidos Políticos, em 1995, a proposição de revisão da Lei de Anistia, em 2010, e a instituição da Comissão Nacional da Verdade (CNV), em 2011. Neste processo, as vítimas e familiares dos atingidos, e os governos de Fernando Henrique Cardoso, Luiz Inácio Lula da Silva e Dilma Rousseff intentaram, em graus e modos diferentes, promover a investigação e responsabilização pela violação de direitos humanos durante a ditadura militar. No contraponto, permaneceram os participantes do Clube Militar que obliteravam quaisquer iniciativas nesse sentido. Diante da correlação de forças, as memórias registradas, inicialmente contrapostas, foram cedendo lugar a um enquadramento gradativo ao ponto de se tornarem difusas no processo de definição da Justiça de Transição.

\section{PALAVRAS-CHAVE}

Ditadura. Democracia. Memória. Justiça de Transição.

\begin{abstract}
The purpose of the article is to demonstrate how the conciliation mechanism was used to overcome the dictatorship and to return to democracy, impacting the memories built on the authoritarian period, and limiting the conformation of a Transitional Justice in Brazil. The debates on this theme were especially marked by the formation of the Special Committee on Political Deaths and Disappearances in 1995, the proposal to revise the Amnesty Law in 2010 and the establishment of the National Truth Commission (CNV), in 2011. In this process, the victims and relatives of those affected, and the governments of Fernando Henrique Cardoso, Luiz Inácio Lula da Silva and Dilma Rousseff, tried in different degrees and in different ways to promote investigation and accountability for human rights violations during the dictatorship military. In counterpoint, the active and reserve military (through the Military Clubs) remained that obliterated any initiatives in this direction. Faced with the correlation of forces, the recorded memories, initially counterposed, gradually gave way to a gradual framework to the point of becoming diffuse in the process of defining the Transitional Justice.
\end{abstract}

\section{KEYWORDS}

Dictatorship. Democracy. Memory. Transitional Justice.

\section{SUMÁRIO}

Introdução. 1. O registro das memórias na transição negociada. 2. Memórias em disputa. 3. O enquadramento da memória. 4. As conciliações da memória. Considerações finais. Referências.

\footnotetext{
* Professor Substituto da Universidade do Estado da Bahia - UNEB: Campus XX, Brumado-BA. Mestre em Memória, Linguagem e Sociedade pela Universidade Estadual do Sudoeste da Bahia. Advogado.

** Professor Titular no Departamento de História e professor permanente do Programa de Pós-Graduação em Memória: Linguagem e Sociedade (PPGMLS), da Universidade Estadual do Sudoeste da Bahia.
} 


\section{INTRODUÇÃO}

O período compreendido entre 1979 e 1985 foi bastante significativo no Brasil, sobretudo pela intensificação da crise econômica e concomitantemente da reorganização de movimentos coletivos de oposição à ditadura militar. Decerto que a conjuntura não se delineou apenas pelo aumento dos juros, da dívida externa, da crise do petróleo ou do crescimento vertiginoso da inflação, como também, pela pressão dos setores populares sobre os quais incidiram as consequências mais violentas da recessão, todavia a interseção desses fatores determinou, em grande medida, o modo como os governos, os partidos políticos e as lideranças sindicais se posicionaram naquele momento.

Emir Sader (1990) considera que a transição para o regime democrático liberal ocorreu em virtude de um pacto entre as frações da classe dominante e pela adesão de intelectuais da esquerda ao consenso em torno das reformas sociais. Se, por um lado, as gestões de Ernesto Geisel (1974 - 1979) e João Figueiredo (1979 1985) se viram forçadas a promover a abertura "lenta, gradual e segura" para evitar uma convulsão social aguda, por outro, as organizações institucionalizadas dos movimentos sociais foram atropeladas por uma torrente de manifestações populares de ação direta.

Evidentemente há razões para isso. Os setores mais resistentes das Forças Armadas, que apoiaram o golpe de 1964 e administraram o Estado de Segurança Nacional nas duas décadas subsequentes, manietaram os dispositivos jurídicos e políticos da passagem ao governo civil, inclusive, com a intimidação de líderes oposicionistas procedentes do exílio - em virtude da flexibilização alcançada com a Lei de Anistia, em 1979.

\footnotetext{
${ }^{1}$ Todas as expressões foram extraídas de Moreira Alves, Maria Helena. Estado e Oposição no Brasil (1964-1984). Petrópolis, Vozes, 1964.
}

No extremo oposto, as tentativas de articulação para promover a ruptura definitiva esbarravam nas diferenças programáticas, cujos resquícios remontavam aos grupos guerrilheiros extintos na década de 1970. De fato, os opositores da ditadura ainda estavam no estágio de autocrítica.

A conjunção de todos esses fatores levou à transição negociada, conceito adotado pelo politólogo argentino Guillermo Alberto O'Donnell (1989), para se referir às negociações com vistas à permanência na democracia de grupos ligados às ditaduras. Assim sendo, por razões distintas, a conciliação política para o retorno à democracia derivou da impossibilidade de conter os ânimos dos trabalhadores urbanos e rurais demasiadamente sacrificados e exigindo soluções emergenciais. No traço histórico que se desenhou naquelas circunstâncias excluía-se a responsabilização dos crimes cometidos na ditadura e, mais que isso, procrastinava-se o debate acerca da violação dos direitos humanos e da justiça de transição.

Não foram poucos os que registraram, por meios mais diversos, a experiência ditatorial e as diversificadas formas de violência cometidas sistematicamente pelo Estado autocraticamente dirigido por governos militares. Tampouco, se constituíram insignificantes aqueles que, tendo colaborado para a instauração da ditadura, buscaram desqualificar a narrativa dos seus opositores com apontamentos diversos da necessidade de "proteção" da nação brasileira do "inimigo interno" que fomentava o "ateísmo" a "indisciplina" e o "comunismo". 1

Essas memórias registradas eram absolutamente conflitantes e, embora tenham sido escritas por indivíduos, representam grupos identitários tendo como cerne a relação estabelecida com o Estado de Segurança Nacional 
sob os governos militares. Como demonstrado no estudo original de Maurice Halbwachs (2006), as memórias individuais se apoiam na memória dos grupos. Muitas vezes, tais lembranças são registradas e multiplicadas para que se consolidem naquela coletividade. No entanto, para o indivíduo

Não é suficiente reconstituir peça por peça a imagem de um acontecimento do passado para se obter uma lembrança; é necessário que esta reconstrução se opere a partir de dados ou de noções comuns que se encontram tanto no nosso espírito como no dos outros, porque elas passam incessantemente desses para aquele e reciprocamente, o que só é possível se fizeram e continuam a fazer parte de uma mesma sociedade (HALBWACHS, 2006, p. 35).

O registro, por sua vez, é resultado de um esforço intelectual que altera significativamente os acontecimentos, visto que, tal ação é mediada pela posição social daqueles que narram o ocorrido. Além disso, são enormes as possibilidades de fixação das memórias de uma coletividade, entre elas, os registros manuscritos, impressos ou audiovisuais.

Os homens vivendo em sociedade usam palavras das quais eles compreendem o significado: é a condição do pensamento coletivo. (...) Nós falamos nossas lembranças antes de as evocar; é a linguagem e todo o sistema de convenções sociais que aí estão solidários que nos permitem, a cada instante, reconstruir nosso passado (Halbwachs, 1952, p. 279).

Todavia, ao proceder ao registro, várias informações se perdem, intencionalmente ou não, durante a elaboração de livros, diários, filmes, documentários, músicas, etc. A maneira como os fatos históricos são mantidos ou apagados da memória de uma sociedade dependem, em grande parte, da correlação de forças políticas no momento em que são registradas. Por isso, nesse mesmo período se estabeleceu uma disputa de memórias sobre a ditadura militar, todavia, permeada de lacunas, omissões, silenciamentos e dissimulações.

Ocorre que, paralelamente à evocação e assentamento das memórias sobre a ditadura militar no Brasil, ocorreram também as negociações visando à transição da ditadura para a democracia; e os sujeitos e fatos históricos envolvidos viriam a estar presentes, algumas décadas depois, na formulação de políticas de memória e de propostas de Justiça de Transição.

Entretanto, dois fatores essenciais modificaram a forma de apropriação daquelas memórias anteriormente construídas: a coesão opositora se dispersou no delongar do tempo e diversas pessoas que compunham o grupo contrário ao governo militar assumiram posições na burocracia estatal. As transformações ocorridas na caracterização da sociedade e na composição diretiva do país resvalaram para uma visão conformista do passado e uma ação conciliadora no presente.

A pretensão de encadear dois momentos históricos traz consigo a precaução de evitar o anacronismo, no entanto, provida de um arcabouço teórico pode ser esclarecedora dos desafios enfrentados para produzir mecanismos jurídicos de transição no país. Sendo assim, serão apresentados os registros mais significativos das memórias das vítimas de abusos do poder ditatorial e dos militares apontando para o modo como os governos, na passagem entre os séculos $\mathrm{XX}$ e XXI, enquadraram tais memórias num projeto de Justiça de Transição.

\section{O REGISTRO DAS MEMÓRIAS NA TRANSIÇÃO NEGOCIADA}

Com o enfraquecimento da ditadura e o início da abertura no país, impôs-se entre as forças políticas e segmentos sociais o debate e a disputa sobre qual modelo de república viria a ser constituída no Brasil. Uma democracia simplesmente representativa ou realmente 
participativa? Uma República que buscaria encarar os problemas vivenciados nos anos de chumbo e superá-los coletivamente ou que pregaria uma falsa conciliação imposta?

Estes embates se deram na discussão sobre a Anistia, na disputa entre as eleições diretas $v s$ indiretas de 1985 e no bojo da Assembleia Nacional Constituinte de 1987/1988. Tais processos conformaram as bases fundantes da chamada Justiça de Transição no Brasil. Marcelo Torelly define a Justiça de Transição como:

[...] uma série de iniciativas empreendidas por via dos planos internacional, regional ou interno, nos países em processo de liberalização ou democratização, englobando suas políticas públicas, suas reformas legislativas e o funcionamento de seu sistema de justiça, para garantir que a mudança política seja bem-sucedida e que, ao final dela, não exista apenas uma democracia eleitoral (caracterizada por eleições procedimentalmente equitativas), mas, sim, um Estado de Direito na acepção substancial do tema (TORELLY, 2012, p. 105).

Assim, as políticas públicas de resgate e reconstrução da memória, de indenizações às vítimas da ditadura, de reformas sobre as instituições construídas/alteradas entre 1964 e 1985, e essencialmente de (não) responsabilização civil, criminal e administrativa dos agentes de estado, passaram a ser foco de homéricas batalhas.

Como marcos institucionais destas celeumas pode-se destacar a constituição da Comissão Especial de Mortos e Desaparecidos Políticos (1995), a composição da Comissão de Anistia (2001), a constituição do Programa Nacional de Direitos Humanos - PNDH-3 (2009), o Julgamento da ADPF $153^{2}$ (que julgou a receptividade/constitucionalidade da Lei de Anistia em 2010), o Julgamento do caso Gomes Lund e outros vs Brasil pela Corte Interamericana

\footnotetext{
${ }^{2}$ A Arguição de Descumprimento de Preceito Fundamental é uma ação judicial ajuizada face ao Supremo Tribunal
}

de Direitos Humanos (2010) e a instauração da Comissão Nacional da Verdade (2012).

Percebe-se que em cada uma dessas comissões, produções legislativas ou celeumas judiciais, ocorreram disputas nas quais o cerne em comum era a hegemonia da memória política e das políticas de memória:

Pode-se definir a política de memória de duas maneiras. De forma restrita, consiste de políticas para a verdade e para a justiça (memória oficial ou pública); vista mais amplamente, é sobre como a sociedade interpreta e apropria o passado, em uma tentativa de moldar o seu futuro (memória social). Memória social é a criação de "comunidades imaginadas" e a construção de uma ordem moral. As "políticas de memória" sociais e culturais são parte integral do processo de construção de várias identidades coletivas sociais e políticas, que definem o modo como diferentes grupos sociais veem a política e os objetivos que desejam alcançar no futuro. A memória é uma luta sobre o poder e sobre quem decide o futuro, já que aquilo que as sociedades lembram e esquecem determina suas opções futuras. Mitos e memórias definem o âmbito e a natureza da ação, reordenam a realidade e legitimam o exercício do poder. A política da memória se torna parte do processo de socialização política, ensinando às pessoas como perceber a realidade política e as ajudando a assimilar ideias e opiniões. A memória é transmitida por "figuras da autoridade", permitindo processo de aculturação e socialização dos cidadãos que vivem dentro das fronteiras de um Estado. Memórias históricas e lembranças coletivas podem ser instrumentos para legitimar discursos, criar fidelidade e justificar ações políticas (BRITO, 2009, p. 72).

Essa disputa de memórias teve como referencial, além de toda a referida contenda política, a produção literária, científica e audiovisual sobre o tema. Como preleciona Lucileide Cardoso, há um surto memorialístico sobre o período de 64 que tece de um lado a função de "legitimar, no presente, a memoria histórica que se pretendeu dominante no período";

Federal para evitar ou reparar lesão a preceito fundamental da Constituição. 
e do outro a de criar diferentes representações do passado, permitindo a preservação de uma memória social que dispusesse de "mecanismos de sobrevivência para escapar à dominação" (CARDOSO, 1994, p. 179).

Um exemplo que ilustra bem estas disputas literárias ocorreu em torno do Projeto Brasil Nunca Mais. Estudo detalhado dos processos criminais e dados oficiais relacionados a crimes políticos e torturas entre o período de 1964 a 1979, demonstrou de forma cabal o fato de que as autoridades brasileiras tinham total conhecimento do que se passava em seus porões. Tal trabalho consistiu em um esforço clandestino de um grupo de pesquisadores que sistematizaram informações de mais de um milhão de páginas, contidas em 707 processos do Superior Tribunal Militar entre os períodos de 1961 a 1979 (ARNS, 1985, passim). ${ }^{3}$

O relatório Brasil Nunca Mais é, na verdade, uma compilação de memórias individuais, forjadas pela extração de depoimentos transcritos de processos judiciais e coletivizados pela identidade de grupo que adquiria o torturado sob a repressão. No momento da publicação resumida, a preocupação com a disputa de memórias transpareceu, não somente, no cuidado com a metodologia rigorosa $\mathrm{e}$ fidelidade às fontes consultadas, como também nas preocupações com as circunstâncias da evocação do fato lembrado, uma vez que ${ }^{4}$ :

No mundo todo, a questão da repressão política é
quase sempre levantada a partir de denúncias dos
atingidos, ou de relatos elaborados por entidades que
se dedicam à defesa dos Direitos Humanos.
Emotivos ou equilibrados, são testemunhos que
ajudam a revelar uma história oculta. Mas tropeçam,

${ }^{3} \mathrm{Na}$ época, por temor de que o material fundamentador da pesquisa pudesse ser destruído pelos órgãos da repressão política, microfilmes de toda documentação foram remetidos ao exterior. Hoje este acervo faz parte do Arquivo Público do Estado de São Paulo.

${ }^{4} \mathrm{O}$ denominado projeto B foi publicado em livro contendo, de forma resumida, as informações recolhidas pela Arquidiocese de São Paulo, com a colaboração de às vezes, na desconfiança daqueles que alegam serem depoimentos tendenciosos, por partirem de vítimas que, na sua maioria, teriam motivações políticas. (ARNS, 1985, p. 22)

Alguns fatores, porém, são destacados ao longo da apresentação do relatório, a exemplo de muitos juízes auditores que determinavam a não transcrição do depoimento prestado pelo preso, ou ainda de advogados que aconselhavam seus clientes a não relatarem os suplícios para terem a possibilidade de redução da pena ou liberdade provisória.

Contudo a questão essencial é demonstrada numa passagem que ressalta ser a denúncia da tortura, antes de tudo, um ato de coragem. Isso se deve não apenas às condições políticas do país, naquele momento, mas, sobretudo, devido à estrutura do Estado, v.g., a manipulação feita pelo Poder Judiciário, alterando a legislação de acordo com os interesses da classe dirigente e buscando manter o poder dos militares:

O ato de denunciar nos tribunais militares a violência
sofrida representava não só a provável volta às
câmaras de tortura ou ameaça de familiares, como o
possível aumento da pena e até mesmo um risco de
morte. (ARNS, 1985, p. 21 )

Portanto, deve-se algum crédito ao registro feito por dezenas de pessoas que testemunharam o sofrimento de outras centenas de indivíduos, cujos depoimentos foram reforçados, por diversas vezes, em situações análogas por outros torturados. Evidentemente os grupos militares, que promoveram a tortura como método sistemático de obtenção de informações para assegurar a permanência do Estado de Segurança

advogados dos presos políticos e testemunhas, ou seja, somente é somente uma parte das 6.891 páginas, contendo 1.843 depoimentos de pessoas que presenciaram ou foram, elas mesmas, torturadas, mortas ou desaparecidas. A pesquisa catalogou 310 diferentes recursos utilizados para impor sofrimento físico ou mental aos presos e constatou 236 locais onde os direitos à dignidade humana foram ignorados. 
Nacional, não foram condescendentes com os religiosos que agruparam dados tão incisivos sobre a tortura no projeto Brasil Nunca Mais.

Após a sua publicação, Marco Pollo Giordani, agente da repressão, lançou em 1986 o livro Brasil: Sempre (Porto Alegre: Editora Tchê). Em uma clara alusão e contraposição à supracitada obra, o autor buscou criticar a atuação da oposição (essencialmente os setores ligados ao comunismo internacional), fazendo uma defesa intransigente dos governos militares.

Neste mesmo ano, o Exército brasileiro preparou um documento interno que pudesse rebater o BNM. O projeto foi elaborado em sigilo e recebeu o nome de ORVIL (palavra livro ao contrário), contendo informações dos arquivos secretos das Forças Armadas sobre os atos e atentados cometidos pela oposição. Concluído em 1988 (no clima de redemocratização), a sua divulgação foi proibida, sendo arquivado como material secreto do Exército ${ }^{5}$.

Além destes documentos de mais fôlego, ainda durante a exceção e a reabertura, diversos livros de memórias individuais foram publicados tanto pelos atingidos pela ditadura, bem como pelos agentes da repressão. "Essas obras não são meros discursos que refletem a realidade política e social vivenciadas pelos seus agentes. São também instrumentos de transformação da realidade no presente, tecendo distintas leituras (e releituras) do momento crítico" (CARDOSO, 1994, p. 180).

Mesmo essas memórias individuais, expressas em livros autobiográficos, não podem ser encaradas de forma isolada. Efetivamente, cada um desses indivíduos (conscientemente ou não) faz parte de grupos sociais que reproduzem suas ideologias próprias e, por conseguinte, as externalizam em suas memórias sociais:

\footnotetext{
${ }^{5}$ Recentemente o livro foi publicado pelo Tentente-Coronel da reserva Licio Augusto Ribeiro, com o nome de "ORVIL - Tentativas de tomada do poder" - Editora Schoba.
}

\begin{abstract}
Nossas lembranças permanecem coletivas e nos são lembradas por outros, ainda que se trate de eventos em que somente nós estivemos envolvidos e objetos que somente nós vimos. Isto acontece porque jamais estamos sós. Não é preciso que outros estejam presentes, materialmente distintos de nós, porque sempre levamos conosco certa quantidade de pessoas que não se confundem. (Halbwachs, 2006, p. 30).
\end{abstract}

Essas memórias são formadas a partir do conjunto de práticas, costumes, valores, noções, linguagem, experiências e sociabilidades colocadas em funcionamento no interior do grupo. Atuam como pontos de referência para a construção subjetiva de lembranças e determinam o que deve ser lembrado, esquecido, silenciado ou comemorado pelas pessoas (RIOS, 2013, p. 6).

\section{MEMÓRIAS EM DISPUTA}

As memórias são regidas por identificação com um grupo relativamente coeso e, portanto, sujeito a comparações com memórias de outros blocos contemporâneos do mesmo contexto histórico. Contudo, não se trata de uma operação meramente mnemônica que se processa mecanicamente a depender da capacidade cognitiva de cada indivíduo. As distintas lembranças derivam de intencionalidades que buscam representar no presente um passado deveras conveniente:

\footnotetext{
Chegamos, simetricamente, da ideia de um passado visível a um passado invisível; de um passado coeso a um passado que vivemos como rompimento; de uma história que era procurada na continuidade de uma memória a uma memória que se projeta na descontinuidade de uma história. O passado nos é dado como radicalmente outro, ele é esse mundo do qual estamos desligados para sempre" (NORA, 1993. p. 18).
} 
Essencialmente dois grupos sociais representam a polarização de posicionamentos conformadas face ao período ditatorial. O primeiro deles tem como base os militares que executaram o golpe de 1964 e aqueles que participaram dos governos ditatoriais defendendo suas bandeiras. Ainda fazem parte deste grupo social, as novas gerações de militares que legitimam e reivindicam o golpe, os Clubes Militares, políticos de extrema direita, grupos anticomunistas, dentre outros. O que os unifica é fundamentalmente a Doutrina de Segurança Nacional - baseada na luta contra o comunismo e no crescimento econômico da nação por meio de uma agenda burguesa para o Estado.

A sua memória é marcada pelo discurso de legitimação da intervenção militar de 1964 e da negação ou, pelo menos, da justificativa do uso da tortura durante a ditadura. A fundamentação é de que as perversidades cometidas não se configuraram enquanto uma regra do regime, mas sim uma exceção praticada por sádicos e grupos à margem do controle estatal. ${ }^{6}$

A obra que sintetiza a memória dos militares é, certamente, "A verdade sufocada: a História que a esquerda não quer que o Brasil conheça", do coronel reformado Carlos Alberto Brilhante Ustra - título que chegou a ser a sexta obra de não ficção mais vendida no Brasil em 2016, segundo o ranking do Jornal Folha de São Paulo (MEIRELES e GENESTRETI, 2016). ${ }^{7}$

$\mathrm{O}$ volume de seiscentas páginas tem o objetivo claro de disputar a memória, definir e adjetivar os opositores. O contraponto é sempre feito a partir das lembranças registradas dos sobreviventes ou grupos de direitos humanos. No entanto, chama atenção a preocupação com o peso

\footnotetext{
${ }^{6} \mathrm{O}$ relatório da Comissão Nacional da Verdade comprovou que a tortura efetuada pela repressão seguia a uma cadeia de comando, havendo inclusive envio de agentes para aperfeiçoamento dessas técnicas no exterior.
}

das memórias alheias e o recuo dos governos após a transição negociada:

\begin{abstract}
Um longo processo de justificativas e autocríticas extravasou em livros, depoimentos, entrevistas, filmes e em toda a sorte de manifestações feitas pelos próprios personagens ou por escribas simpatizantes e engajados. Ainda no exílio e aproveitando-se do apoio de governos comunistas e da esquerda internacional, os fracassados de 64 e os derrotados na luta armada do final dos anos 60 e início da década de 70 desfilaram suas versões e suas falácias que ganharam destaque e credibilidade por não ter havido dos governos pos-64 o necessário empenho em apresentar, em sua verdadeira dimensão, os lances e os acontecimentos que marcaram a mais longa e a mais séria tentativa de implantar no Brasil uma ditadura de inspiração marxista-leninista (USTRA, 2016, p. 23).
\end{abstract}

Ao longo do texto estão descritas todas as ações do Partido Comunista do Brasil (PCB), da Aliança Nacional Libertadora (ALN) e das organizações guerrilheiras que atuaram entre 1978 e 1973, bem como as políticas de reparação e o processo de Justiça de Transição.

$\mathrm{O}$ enfoque nas ações violentas dos grupos guerrilheiros tende a equilibrar a violência física e psicológica perpetrada por agentes do Estado com as ações dos grupos que optaram por combater a ditadura pela via armada. A comparação, envolvendo "aqueles que foram imolados por terem atravessado o caminho de terroristas que não tinham escrúpulos em matar pela 'causa"” (USTRA, 2016, p. 511), apresenta um número de 120 mortos e 343 feridos, entre os quais, curiosamente, consta um número elevado de participantes de organizações guerrilheiras que foram mortos ou feridos durantes as operações militares. ${ }^{8}$

\footnotetext{
${ }^{7}$ A referida obra teve sua primeira edição em 2006, editada pelo próprio autor, no Rio de Janeiro. Ao longo de dez anos foram dez reedições e uma tiragem de vinte mil exemplares. ${ }^{8} \mathrm{O}$ capítulo "vítimas do terrorismo" tem quatorze páginas entre as quais, pelo menos dez, possuem quadros demonstrativos com data da ocorrência, nome completo,
} 
Fica clara a intenção de manipular os dados para registrar a memória de uma versão deformada dos fatos. Evidentemente, tratava-se de uma intensa disputa para que em momentos decisivos do presente, nos quais se definia o pagamento de indenizações e a responsabilização do Estado, prevalecesse a memória que exaltasse os conspiradores de 1964 e infligisse a culpa aos presos, banidos, exilados, torturados ou assassinados durante o período de exceção que sucedeu ao golpe.

A isso se denomina ideologia, ou seja, uma consciência falsa para ocultação da realidade promovida por meio de ferramentas simbólicas, como a memória, para a manutenção das relações de dominação. Não por acaso, a semelhança entre a situação real de desrespeito aos direitos humanos e a criação de uma circunstância abstrata mediante o uso da retórica, pode alterar toda a visão do passado. Segundo consta na publicação citada:

Há anos lutamos para que os familiares dessas vítimas sejam indenizados, como aconteceu com os dos subversivos e terroristas. Infelizmente tem sido uma luta inglória, ignorada pela mídia e desconhecida pela sociedade. A Comissão Especial, instituída pelo governo, decide quem deve ou não ser contemplado com pensões e indenizações pagas pelos cofres públicos. Essa comissão só reconhece como vítimas aqueles que lutaram para implantar no Brasil uma ditadura de cunho marxista-leninista. Com isso demonstra, claramente, a diferença de tratamento entre vencidos e vencedores, cria ressentimentos e contribui para que o esquecimento e paz, propostos pela Lei de Anistia, não sejam alcançados (USTRA, 2016, p. 522).

A menção proposital à Justiça de Transição que, em tese, teria se configurado com a transição negociada e dentro do contexto especificado anteriormente, explicita o desejo de perpetuação da memória dos militares, do seu enquadramento pelo governo e da manutenção do status quo do grupo social representante da autocracia militar. As estratégias continuam sendo as mesmas: desqualificar o oponente e inverter, como numa câmara escura de fotografia, o sentido jurídico das reparações.

O mesmo autor já havia publicado, em 2003, um opúsculo chamado "Rompendo o silêncio", de aproximadamente duzentas páginas, para confrontar Elizabeth Mendes de Oliveira, a atriz e deputada federal Bete Mendes, que durante uma visita ao Uruguai, juntamente com a comitiva presidencial de José Sarney, em 1985, havia reconhecido o "major Tibiriçá", na verdade o coronel Carlos Alberto Brilhante Ustra, atuando no posto de adido militar do Brasil naquele país.

Sem muito esforço é possível perceber, na narrativa do fato, algumas questões inerentes aos problemas postos na introdução a este texto, tais como a permanência de indivíduos da autocracia militar nas instituições democráticas após a transição acordada e o confronto explícito de memórias que teimam em contrariar a negociação política que foi possível realizar nos anos 1980.

O sarcasmo é mais um mecanismo na engrenagem de reconstrução das memórias sobre a ditadura militar, pois, ao mesmo tempo em que o autor justifica que não tinha como usar "punhos de renda e luvas de pelica" para combater os comunistas, ele se considera injustiçado com a ingratidão de jovens que teriam sido "aliciados" por raposas marxistas e "advertidos" a abandonarem os arroubos juvenis. Ao longo de quatorze páginas é descrita a participação de Bete Mendes na Vanguarda Armada Revolucionária Palmares (VAR-PALMARES), os trechos das declarações prestadas pela prisioneira no Destacamento de Operações de Informação (DOI), no qual atuava o propositor das memórias, e as cópias do Inquérito Policial Militar instaurado na 19. ${ }^{a}$ Auditoria da 2a. Circunscrição

circunstâncias da morte, profissão e local onde se registrou o fato. 
Judiciária Militar, em São Paulo, constando que o militar em questão teria testemunhado em favor da tese de aliciamento e beneficiado os jovens acusados. ${ }^{9}$

Segundo Brilhante Ustra, o interrogatório de Bete Mendes se deu num ambiente amistoso:

O meu primeiro dia como Comandante do DOI foi cansativo e extenuante. Procurei me ambientar, visitar parte de suas instalações, estudar as operações em andamento e me inteirar da situação de cada preso. No dia seguinte após a ambientação geral, já estava em condições de tomar algumas decisões e de dar a continuidade necessária ao nosso trabalho. Eram aproximadamente 19:00 horas quando consegui um tempo para conversar com alguns jovens da VAR-PALMARES, oito rapazes e cinco moças que haviam sido presos no dia anterior, decorrente de investigações mandadas proceder por meu antecessor, Major Waldyr Coelho [...]. Inicialmente conversei com os rapazes [...]. A seguir, fui ao local onde estavam as cinco moças, um quarto no segundo andar do nosso prédio. Conversei amigavelmente com elas. Perguntei seus nomes, onde residiam, colégios onde estudavam, profissão dos seus pais e o motivo da sua prisão. Elas eram bastante jovens, no máximo com 21 anos de idade (USTRA, 2003, p. 147).

Após reconhecer a atriz, o diálogo centralizou-se na personagem Renata, da telenovela Beto Rockfeller, da qual Bete Mendes fazia parte do elenco. Desacreditado nos desvios daqueles jovens pueris e imaturos, oficial do II Exército teria refletido o seguinte:

Fui para casa, no meu segundo dia de DOI/CODI, pensando no problema desses jovens e nas suas famílias. Quanta ansiedade, quantos sofrimentos esses pais estariam sentindo a partir do momento em que souberam da prisão e da incomunicabilidade de seus filhos! (USTRA, 2003, p. 147)

\footnotetext{
${ }^{9}$ O Destacamento de Operações de Informação (DOI) tinha como objetivo investigar, encontrar, prender e interrogar suspeitos de cometer crimes contra a Segurança Nacional e o Centro de Operações de Defesa Interna (CODI) coordenava as operações e analisava as informações colhidas nos interrogatórios. A junção dos dois órgãos
}

No entanto, constrangida com o encontro no Uruguai e, ainda mais, com a posição de Brilhante Ustra nas instituições militares do Brasil, a deputada retornou ao país disposta a divulgar na imprensa os crimes cometidos contra ela. Em carta enviada a José Sarney estão explícitas as razões da denúncia:

[...] não posso calar-me diante da constatação de uma realidade que reabriu em mim profunda e dolorosa ferida. Na Embaixada do Brasil no Uruguai serve como Adido Militar o coronel Brilhante Ustra, personagem famoso do regime passado por sua disposição firme em comandar e participar de sessões de tortura a presos políticos. Digo-o, Presidente, com conhecimento de causa: fui torturada por ele (USTRA, 2003, p. 11 e 12).

O silêncio rompido refere-se à objeção da memória de uma vítima da tortura que não consegue se conciliar com a transição democrática quando se defronta com o seu algoz. Este distanciamento e negação da tortura podem ser explicados, já que esse tipo de sevícia, mesmo em tempos de guerra, é extremamente reprovável e quase sempre inconfessável. "Quem torturou não fala das torturas a amigos e familiares, nem se vangloria diretamente disso em entrevistas a jornalistas. Na sua solidão, os torturadores falam apenas com os próprios fantasmas, seus companheiros eternos de trevas" (CFMDP, 2001, p. 115).

Ressalta-se ainda que as declarações atuais dos militares golpistas são carregadas de mágoas, conformando uma espécie de memória ressentida pelo fato de terem "ganhado nas armas, mas perdido nas letras". O revanchismo das vítimas estaria caracterizado na insistência em se falar

ocorreu em 1969 e Carlos Brilhante Ustra comandou as operações, na jurisdição do II Exército, em São Paulo, entre 1970 e 1974. A partir de 1969, os crimes contra a Segurança Nacional passaram a ser julgados por tribunais militares, em auditorias militares que se vinculavam a uma Circunscrição Judiciária Militar (CJM). 
sobre os porões da ditadura. Estaria na cobrança incessante pela punição aos torturadores. O princípio da anistia de "zerar as contas" teria sido violado, e "somente os vitoriosos esqueceram" (MARTINS FILHO, 2002, p. 180).

Outro ponto de disputa memorialístico e ideológico se dá em torno da nomenclatura do ocorrido em 1964. Para os que reivindicam e/ou reproduzem essa memoria social não aconteceu um golpe, mas sim uma revolução:

Esquecer a Revolução de 1964 é uma atitude de capitulação moral e intelectual. É ocultar das atuais gerações o papel exemplar das Forças Armadas, impedindo a criação da república sindicalista e da ditadura do proletariado (CLUBE MILITAR, 2015).

Todavia, esta contenda não se resume em uma disputa lexical. A comemoração da "revolução" se configura enquanto disputa ideológica pela significação do passado e uma demarcação da posição de reconhecimento da legitimidade da intervenção, além do não arrependimento face às iniciativas adotadas à época.

Em contradição a este grupo social, existe um segundo agrupamento que tem como embrião as vítimas da ditadura e seus familiares. Este núcleo central foi quem investigou as mortes, sistematizou documentos e protagonizou as principais ações de Justiça de Transição no Brasil, configurando-se como a memória viva da oposição à ditadura. Advém que em torno deles aglutinaram-se os movimentos de Direitos Humanos, a OAB, os partidos políticos de esquerda, os grupos e pessoas que participaram dos escrachos aos torturadores, os Comitês de Memória, Verdade e Justiça, dentre outros. ${ }^{10}$

\footnotetext{
${ }^{10}$ Entretanto, apesar da aparente homogeneização dentro dos grupos, é necessário alertar que dentro do próprio grupo existem indivíduos que produziram memórias destoantes das internamente predominantes. Isto porque cada indivíduo tem uma vivência e uma percepção a partir do lugar que ali ocupa, e esse mesmo lugar muda segundo as
}

Contudo, mesmo havendo nos últimos governos democráticos protagonistas políticos que foram atingidos pela ditadura, há que se diferenciá-los dos demais grupos. Enquanto os familiares de vítimas e todos os agrupamentos satélites tem defendido incessantemente a bandeira da punição aos torturadores da ditadura, as reparações às vítimas e reformas institucionais, os governos caminharam pela lógica da conciliação e da esquiva aos conflitos.

Por outro lado, a narrativa assumida por estes governos não foi a da revolução de 64 , mas sim a do golpe. Os militantes não foram tratados como terroristas, mas sim como perseguidos ou vítimas. Estes e outros elementos demonstram que apesar de a política de memória dos governos ter destoado dos familiares de vítimas (ou só serem implementadas após muitos embates e insistência), existe uma identidade entre a narrativa oficial e a memória dos perseguidos.

\section{O ENQUADRAMENTO DA MEMÓRIA}

Para entender esta formulação pode-se recorrer à teoria de Michael Pollak e ao conceito de Memória Enquadrada. Para este teórico, uma das funções da memória coletiva é salvaguardar informações e reforçar sentimentos de pertencimento internos às coletividades.

Com isso forja-se a identidade de cada grupo. A identidade "é o sentido da imagem de si, para si e para o outro. Ela constrói e apresenta aos outros e a si própria, para acreditar na sua própria representação, mas também para ser percebida da maneira como quer ser percebida pelos outros" (POLLAK, 1992, p. 204). Logicamente, a memória é um fator constituinte das identidades individual e coletiva.

relações que se mantém com outros ambientes (HALBWACHS, 2006, p. 69). Assim, a memória se modifica e se rearticula conforme posição que se ocupa e as relações que se estabelece nos diferentes grupos de que participa. 
As práticas podem mudar ao longo do tempo, mas para manter a sua identidade, os grupos abrem mão do mecanismo do enquadramento das memórias. Esse enquadramento da memória é feito por membros especiais do grupo, responsáveis pela transmissão dos fatos do passado, de controle da imagem. Esse trabalho implica uma oposição entre o objetivo e o subjetivo. É preciso separar a reconstrução dos fatos e os sentimentos pessoais e escolher testemunhas confiáveis para relatar os fatos e transmiti-los ao público, fazendo o controle da memória (POLLAK, 1989, p. 9 e 10). O enquadramento solidifica e guarda a memória a partir desses pontos de referência.

Pode-se afirmar que este enquadramento se deu a partir da criação da Comissão Especial de Mortos e Desaparecidos Políticos e da criação da Comissão de Direitos Humanos no Congresso Nacional, saindo do âmbito essencialmente social para o âmbito institucional - com digressões no parlamento. A memória enquadrada foi reproduzida pelos governos, igrejas, judiciário, mídia, dentre outros.

Os grupos das memórias enquadradas e dos familiares de vítimas se ancoram um no outro pra lembrar. Acaba que o grupo dos familiares está imerso (e disputando) no grupo da memoria enquadrada. Por sua vez, o grupo da memória enquadrada se apoia nos familiares para poder lembrar. Apesar das diferenças, isto forma uma identidade em comum - balizada no sofrimento da tortura, nas memórias das organizações políticas de oposição à ditadura, etc.

É importante ressaltar que a CEMDP e a Comissão de Anistia reproduzem a memória e a política de memórias das vítimas e familiares, demonstrando que dentro de uma mesma institucionalidade podem coexistir diversas memórias.

Outrossim, pode-se concluir que a batalha das memórias nos trabalhos da Comissão Nacional da Verdade se deu entre três coletividades: 1) a memória dos militares e civis golpistas; 2) a memória das vítimas, familiares de vítimas e agrupamentos satélites; e 3) a memória enquadrada dos governos.

Entre os dois primeiros, houve oposição e confronto tanto no que tange à identidade, como às políticas de memória. Entre o primeiro e o terceiro grupo, não há qualquer identidade, mas subsistem relações políticas, e uma espécie de complacência em relação às políticas de memória. Já entre os dois últimos grupos existe uma similitude de identidade, mas as concepções e práticas de políticas de memória se mostraram convergentes somente até o ponto das reparações e das políticas de memória e verdade - divergindo quanto às responsabilizações e às reformas institucionais.

Isto pode ser evidenciado na publicação do Relatório Final da Comissão Nacional da Verdade. As recomendações do referido relatório tiveram o objetivo de indicar, para o Poder Público e para a sociedade, quais são as pendências que ainda existem no país, de modo que se possa vir a concretizar as medidas necessárias para o avanço da Justiça de Transição.

Ao se analisar o seu conteúdo, constata-se que todas as recomendações da CNV caminharam em sintonia com os anseios das vítimas e familiares de vítimas, sugerindo a continuidade da política de memória, da busca pelos desaparecidos, pela recuperação e publicização dos arquivos da ditadura, pela renomeação dos logradouros públicos que levam nomes de torturadores, dentre outras.

Este documento oficial reconheceu a culpa do próprio Estado brasileiro pelos crimes cometido, e também trouxe em seu bojo recomendações contundentes de alterações legislativas, reformas administrativas e políticas públicas de preservação da memória. Além disso, mesmo sabendo da impossibilidade atual (ou, no mínimo, da dificuldade) de reversão da questão judicial, foi feita uma demarcação de 
posicionamento favorável à responsabilização jurídica dos agentes públicos que deram causa às violações de direitos humanos (BRASIL, 2014, p. 965).

Numa conjuntura em que, mesmo sabendo do entendimento do STF de anistia aos torturadores, e na qual a Comissão da Verdade estava sob forte pressão para que se omitisse sobre a matéria, a recomendação sobre a responsabilização possui um valor simbólico significativo. Destaca-se também que, no bojo da $\mathrm{CNV}$, essa era a principal reivindicação e sugestão de recomendação por parte das vítimas e familiares de vítimas, e dos movimentos de Direitos Humanos.

Além disto, existem algumas recomendações que aparentemente não tem ligação com a pauta da memória e verdade (como o fortalecimento das Defensorias Públicas, desmilitarização das Polícias estaduais, e outras), mas que estão sintonizadas às diretrizes dos Direitos Humanos e às reivindicações dos grupos que se apoiam em familiares e memória das vítimas.

No processo prévio, de construção e composição da Comissão Nacional da Verdade, prevaleceram os anseios dos grupos conciliadores, demonstrando a força que o grupo social dos militares e civis golpistas ainda possui na sociedade brasileira. Todavia, com a entrega do relatório final (e essencialmente com a recomendação contundente de punição aos torturadores), restou claro que a $\mathrm{CNV}$ reproduziu e reivindicou a memória social e as políticas de memórias formuladas pelas vítimas, seus familiares e agrupamentos satélites.

Destarte, compreende-se que o pacto é o elemento teórico central que conduz a discussão da memória no Brasil. O que determina os rumos da organização da memoria política e das políticas de memória é eminentemente a correlação de forças e a capacidade de pressão/articulação das três principais coletividades sociais que disputam este tema no país.

\section{AS CONCILIAÇÕES DA MEMÓRIA}

O nascedouro da memória enquadrada é a conciliação de interesses para a transição negociada e o registro mnemônico é "legitimação" para a posteridade de uma versão do passado fixada na escrita. Mas, de que modo as memórias registradas transitaram da disputa aberta para um enquadramento institucional? A resposta é tão delicada quanto a proposição da questão.

Cabe antecipar que o resgate da memória não está destituído do seu lugar político e social, portanto, as lembranças sobre a ditadura militar no Brasil têm, entre o presente e o passado, um filtro que alteram significativamente a compreensão dos sujeitos envolvidos no fato.

A memória dos militares e civis golpistas se mantém praticamente intacta, no entanto, atualizada com o escopo da discussão sobre os direitos humanos e diante da submissão das Forças Armadas ao comando civil e outra Constituição. A memória das vítimas, familiares de vítimas e agrupamentos satélites é ainda permeada de sofrimento e ausências, todavia muito pulverizada em virtude do delongado período de reivindicações com escassos resultados e uma sociedade, em geral, desmobilizada para tratar do tema. Por sua vez, a memória enquadrada dos governos é resultante da conciliação original e desdobramentos seguintes que impôs a institucionalização do tema, mediante a inserção nas referidas instituições de grupos e mecanismos oriundos das disputas anteriores.

Portanto, as diferentes formas de lembrar a ditadura militar no Brasil, associadas aos grupos supracitados, agregam, concomitantemente, elementos de conciliação e disputa. O enquadramento é o ponto de convergência entre 
fenômenos aparentemente distintos, visto que, são os governos e as instituições a eles subordinadas que produzem as políticas de memória sobre os fatos sociais relevantes e, ao mesmo tempo, organizam e executam as formulações consoantes à Justiça de Transição para promover a estabilidade política e social do país.

O registro de memórias dos militares e civis que promoveram a destituição do presidente João Goulart, em 1964, e mantiveram o país sob a ditadura nas duas décadas subsequentes é, inevitavelmente, a reconstituição de sua visão sobre o período. Todavia há sempre um elemento justificador da intervenção violenta e cruel para dizimar centenas de pessoas que se opunham aos governos militares. Quase sempre o interesse coletivo da segurança nacional é posto em evidência e polarizado com os perigos da ameaça comunista.

Em parte da imprensa, o debate tem se constituído pari passu com a memória disseminada pelos militares herdeiros da autocracia burguesa instalada em 1964. Quando a revisão da Lei de Anistia, mote basilar da discussão sobre a Justiça de Transição no Brasil, foi proposta, em 2010, pela Ordem dos Advogados do Brasil (OAB) um artigo do general-de-brigada Luiz Eduardo Rocha Paiva, publicado no Estado de São Paulo, continha a seguinte análise:

A revisão da Lei da Anistia, orquestrada no Ministério da Justiça e em sua Secretaria Especial de Direitos Humanos, é facciosa ao propor o julgamento apenas dos que lutaram em defesa do Estado, da lei e da ordem. A busca aos corpos de mortos na guerrilha do Araguaia não teve um nobre propósito humanitário, mas sim o objetivo velado de obter o apoio da sociedade para a revisão da lei. A operação foi aberta à participação dos setores interessados e pesquisou todos os locais solicitados. Concluída a busca infrutífera e mesmo sem indícios de apoio popular, o governo baixou um decreto criando a Comissão da Verdade e abrindo a possibilidade de revisão da lei, cláusula pétrea da estratégia de desgaste das Forças Armadas (PAIVA, 2010).

A interposição da pretensa legitimidade do autoritarismo pretérito dialogando com a função constitucional das Forças Armadas no presente produzem relatos memorialísticos, quase sempre, oriundos de oficiais da reserva e, portanto, sem comando militar, e narrativas dissociadas da discussão sobre os Direitos Humanos, pois implicaria em reconhecer a necessidade de punição nos âmbitos cível e criminal.

Por outro lado, o corporativismo institucional impede que os comandantes das Forças Armadas, no uso de suas atribuições, para cumprimento do dispositivo constitucional, disponibilizem, sem restrições, os arquivos confidenciais em seu poder para que ocorra a responsabilização dos crimes previstos na legislação anterior e atual, nacional e internacional. Consequentemente, há um grupo identitário e solidário em suas memórias que produzem revelações sobre o passado brasileiro consoante com as perspectivas atuais e com forte ingerência nas decisões sobre os métodos da Justiça de Transição a serem adotados no país.

No extremo oposto, as vítimas sobreviventes da violação dos Direitos Humanos e os familiares daqueles que estão desaparecidos ou foram assassinados durante a ditadura militar não tiveram um ambiente social e político propício para impor suas reivindicações, mediante uma pressão popular. Restou-lhes a opção de imergir na institucionalidade e promover as reparações possíveis mediante proposições que eram acatadas ou negadas a depender da correlação de forças no poder.

A concepção de poder refere-se a um governo estatal e sua organização burocrática e militar, que é comandado por uma classe, a burguesia, sendo ela "desde o estabelecimento da grande indústria e do mercado mundial" quem detém a "soberania política exclusiva no Estado representativo moderno". Sendo assim, "o 
governo moderno não é, senão, um comitê para gerir os negócios comuns de toda a classe burguesa”. (MARX E ENGELS, 1983, p. 23)

Em suma, quaisquer que sejam os gestores governamentais, independente de sua origem social, estarão sempre a serviço dos interesses da classe dominante tendo como contraponto, somente, as pressões dos grupos dominados. Desse ponto de vista, as políticas de reparação propostas no período democrático foram extraídas de ações impositivas interpostas pelas vítimas, seus familiares e associados, no entanto, contidas, em grande parte, pela classe dominante que possui um peso considerável nas decisões oficiais, tendo em vista seus interesses de preservar a memória de acordo com a sua versão dos acontecimentos.

Mesmo considerando que uma parte significativa daqueles que compõem os governos municipais, estaduais ou federal, na atualidade, conviveram no Estado Autoritário e, portanto, estão em condições de promover ou influenciar uma Justiça de Transição que atenda aos reclames das vítimas e famílias de perseguidos políticos, sua identificação direta não é mais com a causa primeira. O lugar que hoje representam no interior do Estado está dissociado da condição social que vivenciaram durante as duas décadas de ditadura militar.

Portanto, tem razão o sociólogo francês da escola durkheimiana ao propor que é bastante delicado assumir posição a partir de um lugar diferente daquele com o qual já não nos identificamos:

Assim, se encontrarmos mais tarde membros de uma sociedade que se tornou para nós a tal ponto estranha, por mais que nos encontremos no meio deles, não conseguimos reconstituir com eles o grupo antigo. É como se abordássemos um caminho que percorremos outrora, mas de viés, como se o encarássemos de um ponto de onde nunca o vimos (HALBWACHS, 2006, p. 31).

Aqui se estabelece, portanto, mais um ponto de inflexão entre a disputa e a conciliação, pois é impossível aos governantes democráticos não se sensibilizarem com as demandas dos que tiveram seus direitos conspurcados na fase autoritária anterior, contudo estão sob a tutela de um Estado ainda comprometido por uma aliança mediadora entre os interesses das frações que apoiaram a ditadura $\mathrm{e}$ as demais que prenunciaram a necessidade de transição para a democracia.

É certo que Maurice Halbwachs não tratou dos conflitos entre grupos distintos e o escopo do seu estudo foi, essencialmente, a identificação coletiva da memória. Porém, não parece exagerado observar que a comparação feita pelo autor entre a memória individual e o pertencimento coletivo poderia se aplicar, sem provocar desvios, aos sujeitos que se afastam de um grupo e moldam-se a uma distinta configuração social. Sua proposição original é a seguinte:

Para que nossa memória se beneficie da dos outros,
não basta que nos tragam seus testemunhos; é
preciso também que ela não tenha deixado de
concordar com suas memórias e que haja suficientes
pontos de contato entre ela e as outras, para que a
lembrança que os outros nos trazem possa ser
reconstruída sobre uma base comum
(HALBWACHS, 2006, p. 12).

Em comparação ao que foi dito acima, o sociólogo austríaco Michael Pollak, referindo-se às memórias de franceses deportados durante a Segunda Guerra Mundial, aplicou, sem restrições, o caráter conflitivo aos grupos organizados de resistência ao nazismo, de forma semelhante ao que Halbwachs fez ao construir a conexão entre memória individual e coletiva:

Se é possível o confronto entre a memória individual e a memória dos outros, isso mostra que a memória e a identidade são valores disputados em conflitos sociais e intergrupais, e particularmente em conflitos que opõem grupos políticos diversos (POLLAK, 1992, p. 204-205). 
Depreende-se do exposto que é possível relacionar a construção enquadrada de uma memória dentro do espectro de interesses conflitantes se os grupos em disputa não forem capazes de hegemonizar a projeção de suas lembranças para toda a sociedade. Assim ocorre com as memórias sobre a ditadura militar no Brasil, posto que, em tese, os militares estão limitados pela hierarquia e subordinação ao poder executivo central. O governo tem restrições impostas pelo interesse da classe dominante e as vítimas e os familiares dependem de suas instituições para promover a reparação dos danos sofridos em virtude da imobilidade social a seu favor.

Em síntese, a insuficiência de condições adequadas para a polarização dos interesses de classes no período de transição entre a ditadura e a democracia impactou no modo como as memórias em disputa, nas décadas seguintes, convergiram para a conciliação política pelo alto que, por sua vez, promoveu o enquadramento da memória e as limitações na concepção de uma Justiça de Transição efetivamente capaz de investigar abusos cometidos pelos governos autocráticos e promover, sem restrições, a superação daquele período histórico.

\section{CONSIDERAÇÕES FINAIS}

A transição negociada da ditadura para a democracia tem uma infinidade de motivações e causas que ultrapassam a dimensão e os objetivos de um artigo, todavia, é sempre possível apontar algumas vias interpretativas visando o aprimoramento da pesquisa científica acerca de um evento passado.

A pretensão inicial foi demarcar o impacto da política de conciliação, proposta e executada por militares e civis, na década de 1970, sobre as memórias e a constituição da Justiça de Transição no Brasil. Parece pertinente afirmar que tal empreendimento apartou, de um lado, vitimas de abusos contra os direitos humanos e familiares de pessoas mortas em decorrência da mesma situação e, de outro, os governos democráticos constituídos pela transição negociada.

Permaneceu, contudo, a profunda divergência entre os militares que se estabeleceram com o golpe de 1964 e os opositores que foram torturados juntamente aos familiares de vítimas fatais. Mas os desdobramentos da orquestração institucionalizada após o fim da ditadura movimentaram as peças do xadrez político, fazendo convergir para a mesma direção do poder civis e militares contrários e apoiadores do golpe de 1964.

Evidentemente que essas estruturas esquemáticas que envolvem o estudo não são rígidas e, como foi visto, muitos foram os esforços governamentais para avançar na agenda dos direitos humanos e propiciar uma revisão dos mecanismos da Justiça de Transição em trâmite. Contudo os impedimentos decorrentes da convergência negociada, no passado, restringiram o potencial que a liberdade da democracia formal poderia proporcionar à sociedade brasileira, em geral, e aos que foram alcançados pelo braço repressor do Estado ditatorial, em particular.

As disputas pelas posições no presente perpassam pela fixação de memórias sobre o passado. Sendo assim, o construto mnemônico determina, em algum grau, a condução das estruturas sociais, políticas e econômicas, porquanto, a dominação numa sociedade implica em impor ideias como a generalização, naturalização, ocultação e distorção da realidade.

Fica do exposto a convicção que a transição para a democracia gerou um custo social e político para a sociedade brasileira; contudo ainda estamos no terreno movediço da interposição de memórias sobre a ditadura militar e, diante do desafio que representa a revelação genuína dos fatos que determinaram a imposição autocrática, resta uma severa apreciação das memórias que 
estão se consolidando sobre o passado para que as gerações vindouras não sejam convencidas que todos os regimes são universalmente parecidos, nem acreditem que o autoritarismo é um desdobramento natural da estratificação econômica e, tampouco, tenhamos omissões ou deturpações dos tempos pretéritos.

\section{REFERÊNCIAS}

ARNS, Paulo Evaristo, dom (Org.). Brasil: Nunca Mais. São Paulo: Vozes, 1985.

ARNS, Paulo Evaristo, dom (Org.). Brasil: Nunca Mais. São Paulo: Tomo V, Volume 1, 1985. Datilografado.

ALVES, Maria Helena Moreira. Estado e Oposição no Brasil (1964-1984). Petrópolis, Vozes, 1964.

BRASIL. Comissão Nacional da Verdade. Relatório final. 2014. Disponível em: <http://www.cnv.gov.br/images/pdf/relatorio/volume_1_digital.pdf>. Acesso em: 27 set. 2017.

CARDOSO, Lucileide Costa. Construindo a memória do regime de 64. Revista Brasileira de HistóriaBrasil, 1954-1964. São Paulo, ANPUH - Marco Zero, v. 14, n. 27, 1994.

BRITO, Alexandra Barahona de. Justiça Transicional e a Política da Memória: uma Visão Global. Revista Anistia Política e Justiça de Transição, Brasília, n. 1, jan./jun. 2009. Ministério da Justiça.

CLUBE MILITAR. Não temos o Direito de esquecer. 2015. Disponível em: <http://clubemilitar.com.br/pensamento-do-clube-militar-24/> Acesso em: 25 jun. 2016

COMISSÃO DE FAMILIARES DE MORTOS E DESAPARECIDOS POLÍTICOS. Dossiê Ditadura: Mortos e Desaparecidos Políticos no Brasil (1964-1985). São Paulo: Humanitas/FFLCH/USP, 2001.

HALBWACHS, Maurice. A memória coletiva. Trad. de Beatriz Sidou. São Paulo: Centauro, 2006.

MARX, Karl, e, ENGELS, Friedrich. Obras escolhidas. Volume I. São Paulo: Editora Alfa-Omega, 1983.

MARTINS FILHO, João Roberto. A guerra da memória. A ditadura militar nos depoimentos de militantes e militares. Varia História, UFMG, n. 28, dezembro 2002.

MEIRELES, Maurício e GENESTRETI, Guilherme. Brilhante Ustra é o sexto autor de não ficção mais vendido do país. Folha de São Paulo, São Paulo: 03 de junho de 2016. Disponível em: $<$ http://www1.folha.uol.com.br/ilustrada/2016/06/1777921-brilhante-ustra-e-o-sexto-autor-de-naoficcao-mais-vendido-do-pais.shtml>. Acesso em: 16 out. 2017.

NORA, Pierre. Entre memória e história: a problemática dos lugares. Projeto História. Revista do Programa de Estudos Pós-Graduados em História e do Departamento de História da PUC-SP, São Paulo, n. 10., dez. 1993. 
O’DONNELL, G. El Estado burocrático-autoritario. Buenos Aires: Editorial de Belgrano, 1996.

PAIVA, Luiz Eduardo Rocha. O presidente cederá ao revanchismo? Estado de S. Paulo, São Paulo, 8 jan. 2010. Disponível em: http://www.estadao.com.br/noticias/geral,o-presidente-cedera-aorevanchismo,492356. Acesso em: 16 out. 2017.

POLLAK, Michael. Memória, esquecimento, silêncio. Estudos Históricos, Rio de Janeiro, vol. 2, n. 3 , 1989.

. Memória e identidade social. In: Estudos Históricos, Rio de Janeiro, vol. 5, n. 10, 1992;

RIOS, Fábio. Memória coletiva e lembranças individuais a partir das perspectivas de Maurice Halbwachs, Michael Pollak e Beatriz Sarlo. Revista Intratextos, vol 5, n. 1, p. 1-22, 2013.

SADER, Emir. A transição no Brasil. Da ditadura à democracia? São Paulo: Atual, 1990.

TORELLY, Marcelo D. Justiça de Transição e Estado Constitucional de Direito. Belo Horizonte: Fórum, 2012.

USTRA, Carlos Alberto Brilhante. Rompendo o silêncio. São Paulo: Editora Supervirtual, 2003. . A verdade sufocada. 13. a ed., São Paulo: Editora Ser, 2016.

Recebido em: $23 / 10 / 2017$

Aceito em: 10/07/2018 
